\title{
Hints to the Diagnosis of Mixed Acinar-Endocrine Carcinoma on Pancreatic Fine-Needle Aspiration: Avoiding a Potential Diagnostic Pitfall
}

\author{
Peggy S. Sullivan ${ }^{a}$ Jennifer L. Clebanoff ${ }^{b}$ Sharon L. Hirschowitz ${ }^{a}$ \\ a Department of Pathology and Laboratory Medicine, David Geffen School of Medicine at UCLA, Los Angeles, Calif.,

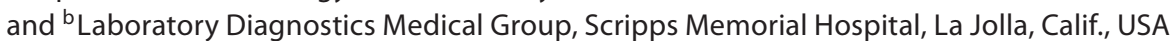

\section{Established Facts}

- Mixed acinar-endocrine carcinoma (MAEC) is a rare mixed tumor of the pancreas defined by both acinar and endocrine cell differentiation.

\section{Novel Insights}

- As MAEC may have a more aggressive clinical course and different therapeutic implications, distinction of this entity from pancreatic endocrine neoplasm (PEN) on fine-needle aspiration (FNA) is important.

- The following cytomorphologic features may be helpful in distinguishing MAEC from PEN: macronucleoli, pyknotic cells, mitotic figures, and coarse granules.

- The addition of trypsin or lipase and Ki-67 immunocytochemistry with endocrine markers may be helpful in raising the possibility of MAEC on cytology.

\section{Key Words}

Mixed acinar-endocrine carcinoma • Pancreas cytology • Fine-needle aspiration

\footnotetext{
Abstract

Background: Mixed acinar-endocrine carcinoma (MAEC) is a rare mixed tumor of the pancreas defined by both acinar and endocrine cell differentiation. Case: We present 2 cases of MAEC initially diagnosed as pancreatic endocrine neoplasm on fine-needle aspiration. Both patients were male, aged 51
}

and 75 years, and presented with $16-\mathrm{mm}$ and 6-mm pancreatic masses, respectively. Aspirates showed loose aggregates and dispersed single plasmacytoid cells with moderate nuclear size variation, slightly irregular nuclear contours, fine to coarsely granular chromatin, occasional prominent nucleoli, and scant to moderate finely granular cytoplasm. Rare mitotic figures and pyknotic forms were noted in one of the cases. Endocrine differentiation was confirmed by immunocytochemistry which led to an initial diagnosis of pancreatic endocrine neoplasm. Trypsin and lipase immunocytochemistry were later obtained, confirming a component

\section{KARGER}

E-Mail karger@karger.com

www.karger.com/acy
(C) 2013 S. Karger AG, Basel

0001-5547/13/0573-0296\$38.00/0
Correspondence to: Dr. Peggy S. Sullivan

Department of Pathology and Laboratory Medicine David Geffen School of Medicine at UCLA

10833 Le Conte Avenue, Los Angeles, CA 90095-1732 (USA)

E-Mail psullivan@mednet.ucla.edu 
of acinar cell differentiation. Findings were confirmed on surgical excision. Conclusion: Because of their potentially more aggressive clinical course and different therapeutic implications, MAECs are an important consideration in the differential diagnosis of pancreatic neoplasms. Certain cytomorphologic features and immunocytochemical markers of acinar cell differentiation may be helpful in raising the possibility of MAEC on cytology. Copyright $\Theta 2013$ S. Karger AG, Basel

\section{Background}

MAEC of the pancreas is a mixed tumor defined by the presence of both acinar and endocrine differentiation, each comprising at least $25 \%$ of the neoplasm [1]. MAECs are rare; however, more cases are being recognized, likely due to the increased use of immunohistochemistry (IHC) and greater awareness of the entity. Because MAECs are thought to have a more aggressive clinical course than PENs and systemic therapy may vary between the two entities, it is important to make the distinction between MAEC and PEN on cytology. In this case report, we present two cases of MAEC originally diagnosed as PEN on FNA and discuss the cytomorphologic and immunocytochemical features that may be helpful in distinguishing between the two entities.

\section{Case}

A retrospective search of pathology records from 2001-2011 at UCLA Medical Center (Los Angeles, Calif., USA) identified 3 histologic cases of MAEC. All 3 cases were identified within a single year (2010). Two cases had prior cytology obtained by endoscopic ultrasound-guided (EUS) FNA at UCLA. The third case had prior cytology obtained from an outside hospital reported as a pancreatic neuroendocrine tumor, but smears were not available for review. For cases 1 and 2, cytologic material was obtained in the endoscopy suite via ultrasound guidance with 25 -gauge needles. Aspirated material was smeared onto 8-12 glass slides and immediately fixed in $95 \%$ ethanol for Papanicolaou staining. On-site adequacy assessment was not performed. Needle rinses were processed for a ThinPrep slide.

Additional cytologic material from case 1 was available from an on-site adequacy assessment of a liver mass core biopsy obtained percutaneously via ultrasound guidance with 18-gauge core needles. Touch preparations of the core biopsy were fixed in 95\% ethanol or air-dried for Papanicolaou or Diff-Quik stains. Surgical specimens were obtained as dictated by clinical management and routinely processed for microscopic examination as hematoxylin and eosin-stained slides prepared from formalin-fixed paraffin-embedded tissues.
Table 1. Clinical data and imaging findings in the pancreas

\begin{tabular}{llllll}
\hline & $\begin{array}{l}\text { Sex/age } \\
\text { years }\end{array}$ & Presentation Location & $\begin{array}{l}\text { Size } \\
\mathrm{mm}\end{array}$ & $\begin{array}{l}\text { Ultrasound } \\
\text { findings }\end{array}$ \\
\hline Case 1 & $\mathrm{M} / 75$ & $\begin{array}{l}\text { Liver } \\
\text { transplant, } \\
\text { multiple } \\
\text { masses }\end{array}$ & Genu & 6 & $\begin{array}{l}\text { Hypoechoic } \\
\text { homogeneous } \\
\text { lesion, well- } \\
\text { defined }\end{array}$ \\
\hline Case 2 & $\mathrm{M} / 51$ & $\begin{array}{l}\text { Acute } \\
\text { pancreatitis }\end{array}$ & Body & 16 & $\begin{array}{l}\text { Hypoechoic } \\
\text { mass, well- } \\
\text { circumscribed }\end{array}$ \\
\hline
\end{tabular}

Immunocytochemical stains were performed directly on alcohol-fixed smears or ThinPrep slides. IHC was performed on formalin-fixed paraffin-embedded tissues. Paraffin sections were cut at $2 \mu \mathrm{m}$, picked up on positive charged slides, and baked at $60^{\circ} \mathrm{C}$ for $60 \mathrm{~min}$. Following deparaffinization in xylene and rehydration in graded ethyl alcohols to water, slides were heated at $95^{\circ} \mathrm{C}$ in a vegetable steamer for $25 \mathrm{~min}$ in citrate buffer $\mathrm{pH} 6.0$ (for synaptophysin, chromogranin, and CD56) or EDTA pH 8.0 (for Ki67). IHC was performed on a DAKO autostainer programmed to incubate the primary antibody for $30 \mathrm{~min}$ followed by an Ultravision LP Detection system consisting of post-primary antibody for $10 \mathrm{~min}$ and HRP-polymer for $15 \mathrm{~min}$. Chromogen (diaminobenzidine-hydrogen peroxide) reaction was for $10 \mathrm{~min}$. Dilutions of primary antibodies were as follows: synaptophysin 1:50 (M0776; Dako, Carpenteria, Calif., USA), Ki67 1:100 (M7240; Dako), and chromogranin 1:1,000 (M0861; Dako). IHC for trypsin, lipase, and chymotrypsin was performed by Genzyme Genetics (Los Angeles, Calif., USA) using either a low $\mathrm{pH}$ pretreatment (for chymotrypsin) or a high $\mathrm{pH}$ pretreatment (for lipase and trypsin) for $15 \mathrm{~min}$. Immunohisto- or cytochemistry was performed on a Leica Bondmax autostainer and Bond Refine detection system. Dilutions of primary antibodies were as follows: chymotrypsin 1:500, lipase 1:64,000, and trypsin 1:80,000 (all from QED Bioscience, San Diego, Calif., USA). All slides were counterstained with hematoxylin. Positive and negative controls were run for each block/test and stained appropriately.

\section{Clinical/EUS Findings}

Clinical history and imaging findings are summarized in table 1 . Case 1 is from a 75 year-old male status post liver transplantation 9 years ago for cirrhosis secondary to hepatitis B. An MRI obtained during routine follow-up demonstrated multiple new liver masses and a single cystic pancreatic lesion. The patient underwent a core biopsy with touch preparations of one of the liver masses and an EUS-FNA of the pancreatic lesion.

Case 2 is from a 51 year-old male who presented with unresolved acute pancreatitis. Imaging showed cystic masses in the pancreatic body and tail, suggestive of an acute inflammatory response. EUS-FNA of the pancreas was performed.

Cytopathologic and Immunocytochemical Findings

A summary of the cytomorphologic and immunocytochemical features is shown in table 2. Case 1 showed hypercellular 


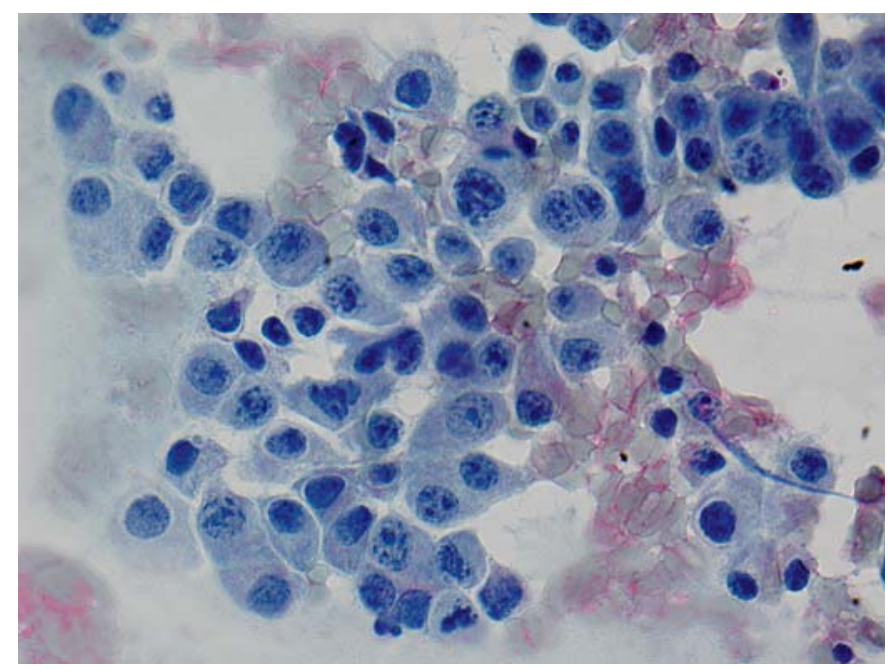

Fig. 1. Pancreas FNA smear from case 1 showing loose aggregates and single plasmacytoid cells with moderate nuclear size variation, stippled to coarse chromatin, occasional macronucleoli, and moderate finely granular cytoplasm. Note an occasional binucleated cell (upper right). Papanicolaou stain. $\times 1,000$.

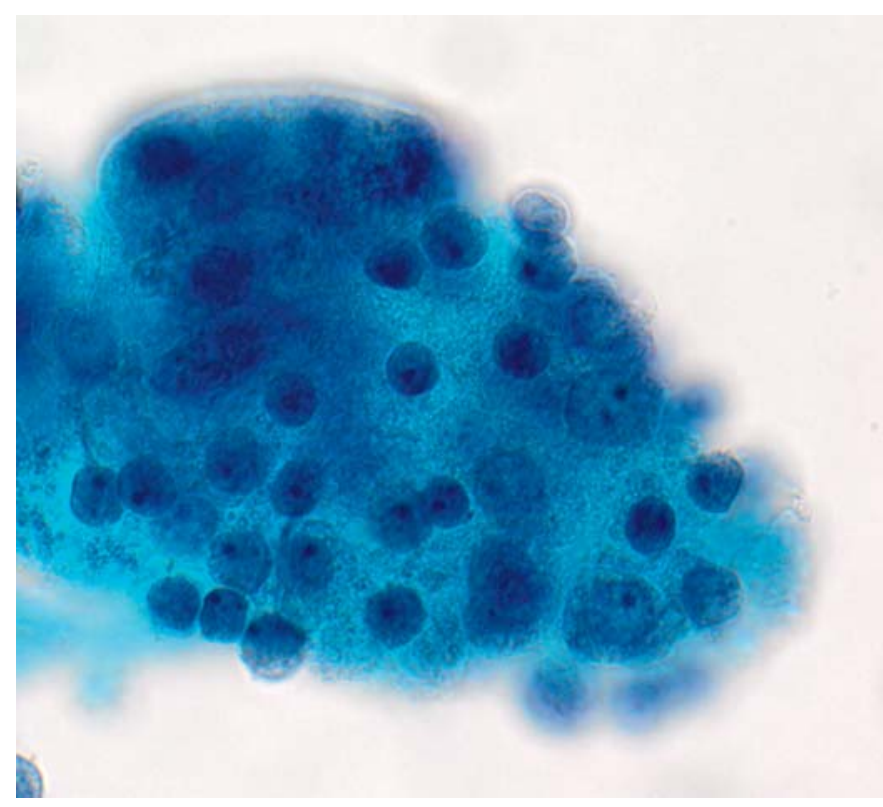

Fig. 3. Pancreas ThinPrep slide from case 2 showing an aggregate of tumor cells with round nuclei, moderate nuclear size variation, slightly irregular nuclear contours, small nucleoli, and moderate granular cytoplasm. Papanicolaou stain. $\times 1,000$.

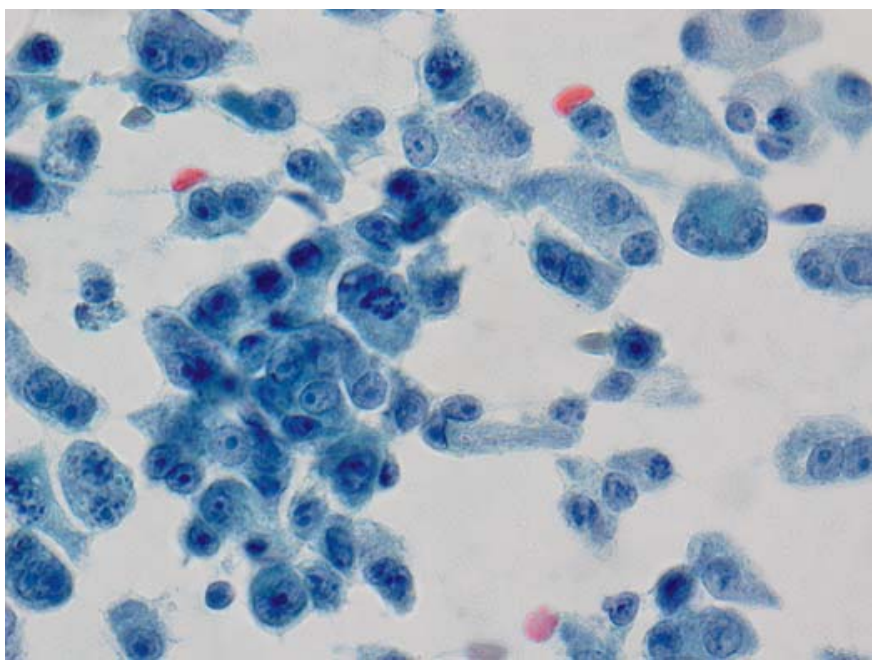

Fig. 2. Liver touch preparation from case 1 showing findings similar to the pancreas smear with more open chromatin, frequent macronucleoli, binucleation, and more abundant tapered cytoplasm. Note the presence of mitotic figures (center). Papanicolaou stain. $\times 1,000$.

smears composed of enlarged plasmacytoid cells arranged in loose aggregates and singly. The cells had round to oval nuclei, moderate nuclear size variation, irregular and angulated nuclear contours, coarsely granular chromatin, and frequent macronucleoli. A suggestion of nuclear molding and 'salt-and-pepper' chromatin was noted. The cytoplasm was moderate to focally abundant and delicate to finely granular. Rare mitotic figures and occasional pyknotic and binucleated forms were noted. The background was relatively clean with scant granular debris and blood (fig. 1).

Touch preparations from the liver mass in case 1 showed similar cytomorphology to the pancreas lesion. In addition, there was increased nuclear pleomorphism, more open chromatin, and more frequent macronucleoli. Mitotic figures and pyknotic cells were more conspicuous. The cytoplasm was more abundant and in some instances tapered with fine to coarse pink-tan granules (fig. 2).

Case 2 showed scant to moderately cellular smears comprised of small plasmacytoid cells in loose aggregates and singly, many as bare nuclei. The cells had round to oval nuclei with mild nuclear size variation, slightly irregular nuclear contours, finely granular 'salt-and-pepper' chromatin, some nuclear molding, and occasional small nucleoli. The cytoplasm was scant and delicate. While some cells had a suggestion of more prominent, frequent nucleoli and increased granular cytoplasm (fig. 3), two cytomorphologically distinct cell populations were not appreciated. No mitotic figures, pyknotic cells, bi-nucleated cells, or necrosis was seen. The background had gastrointestinal epithelial contaminant, obscuring blood, and granular debris.

Cases 1 and 2 were diffusely and strongly positive for synaptophysin. Both cases had an initial FNA diagnosis of PEN. After further discussion with the oncologist regarding the aggressive 
clinical course of the tumor and the need to consider other chemotherapeutic regimens, additional immunocytochemical studies were obtained for case 1 and the diagnosis was revised to MAEC (fig. 4). Additional immunocytochemical studies were obtained for case 2 after review of the final surgical pathology results.

\section{Surgical Pathology Correlation and IHC Findings}

Surgical pathology and IHC findings are summarized in table 3 . The liver core biopsy in case 1 showed relatively uniform large epithelioid to plasmacytoid neoplastic cells arranged in sheets and nests in a fibrotic stroma. The cells had enlarged, vesicular, and somewhat hyperchromatic round to oval nuclei, macronucleoli, and a moderate amount of amphophilic to eosinophilic cytoplasm, some with abundant coarse pink granules. Well-differentiated acinar or endocrine components were not identified. Tumor cells stained strongly for endocrine markers, and a diagnosis of well-differentiated endocrine carcinoma was made. After additional IHC studies were obtained demonstrating strong co-expression of acinar and endocrine markers in all tumor cells, a revised diagnosis of MAEC metastatic to the liver was made.

The tumor in the distal pancreatectomy specimen in case 2 showed small to intermediate neoplastic cells in sheets, nests, and trabeculae with round to oval, somewhat angulated nuclei with granular to focally vesiculated chromatin and small conspicuous nucleoli. The cytoplasm was delicate to focally granular and moderate in amount. Distinct clusters of well-differentiated acinar cells with large round open basally polarized nuclei, macronucleoli, and coarse pink granules were continuous with the neoplasm and did not appear to be entrapped foci of normal parenchyma (fig. 5). The majority of the tumor was positive for synaptophysin (less than $75 \%$ of the tumor, fig. 6), with many cells positive for lipase (greater than 25\% of the tumor, fig. 7), including tumor cells lacking distinct acinar cell histomorphology. Two of 23 lymph nodes removed were positive for tumor that stained strongly for synaptophysin. A lipase stain was negative in the involved nodes. The case was signed out as MAEC with positive lymph nodes involved by well-differentiated endocrine carcinoma.

\section{Discussion}

MAEC is the most common subtype of pancreatic carcinomas with mixed (i.e. acinar, endocrine, and ductal) differentiation. Both acinar and endocrine differentiation must be present, each comprising at least $25 \%$ of the carcinoma by arbitrary definition [1]. Since the first reported case by Ulich et al. [2] in 1982, more than 30 cases (both pancreatic and extra-pancreatic) have been reported in the English literature to date. Our current study reports 2 cytologic cases of pancreatic MAEC with diagnoses rendered in the same year. With the increased use of IHC and greater awareness of this entity, MAEC may be more prevalent than previously thought.

Table 2. Cytomorphologic and immunocytochemistry findings

Case 1

Cytomorphology

Nuclear size variation

Nuclear contours

Chromatin

'Salt-and-pepper'

Nucleoli

Binucleated forms

Cytoplasm amount

Cytoplasm quality

Mitotic figures

Pyknotic forms

Necrosis

Immunocytochemistry

Synaptophysin

Trypsin

Ki67

Lipase

$\mathrm{NP}=$ Not performed.
Case 2

\begin{tabular}{|c|c|}
\hline Moderate & Mild \\
\hline $\begin{array}{l}\text { Irregular and } \\
\text { angulated }\end{array}$ & Slightly irregular \\
\hline Coarsely granular & Finely granular \\
\hline Somewhat & Yes \\
\hline $\begin{array}{l}\text { Frequent } \\
\text { macronucleoli }\end{array}$ & $\begin{array}{l}\text { Occasional } \\
\text { small nucleoli }\end{array}$ \\
\hline Yes & No \\
\hline $\begin{array}{l}\text { Moderate, } \\
\text { focally abundant }\end{array}$ & Scant \\
\hline $\begin{array}{l}\text { Delicate to finely } \\
\text { granular }\end{array}$ & $\begin{array}{l}\text { Delicate to } \\
\text { finely granular }\end{array}$ \\
\hline Rare & None \\
\hline Occasional & None \\
\hline None & None \\
\hline
\end{tabular}

Moderate angulated

Somewhat

macronucleoli

focally abundant

Delicate to finely

Occasional

None

Yes

No

None
Coarsely granula

small nucleoli

Delicate to

finely granular

$+$

$\begin{array}{cl}+ & + \\ + & \mathrm{NP} \\ 40 \% & \mathrm{NP} \\ - & +\end{array}$

NP

$+$
Table 3. Surgical pathology and immunohistochemical findings

\begin{tabular}{|c|c|c|}
\hline & Case 1 & Case 2 \\
\hline \multicolumn{3}{|l|}{ Surgical pathology } \\
\hline Specimen & Liver biopsy & Distal pancreatectomy \\
\hline Acinar component & $100 \%^{\mathrm{a}}$ & $>25 \%$ \\
\hline Endocrine component & $100 \%^{a}$ & $<75 \%$ \\
\hline LVI & Present & Present \\
\hline Mitotic count & $2 / 10 \mathrm{hpf}$ & NP \\
\hline Metastatic site(s) & Liver & Lymph nodes \\
\hline \multicolumn{3}{|l|}{ IHC } \\
\hline Synaptophysin & + & + diffuse \\
\hline Chromogranin & + & + focal \\
\hline CD56 & NP & NP \\
\hline Trypsin & + & + focal \\
\hline Chymotrypsin & + & + focal \\
\hline Lipase & NP & + \\
\hline Ki67 & $40-50 \%$ & $7-11 \%$ \\
\hline
\end{tabular}

hpf = High power fields; LVI = lymph/vascular space invasion; $\mathrm{NP}=$ not performed.

a Morphologically discrete acinar and endocrine components were not identified. Tumor cells demonstrated dual expression of both acinar and endocrine cell markers. 


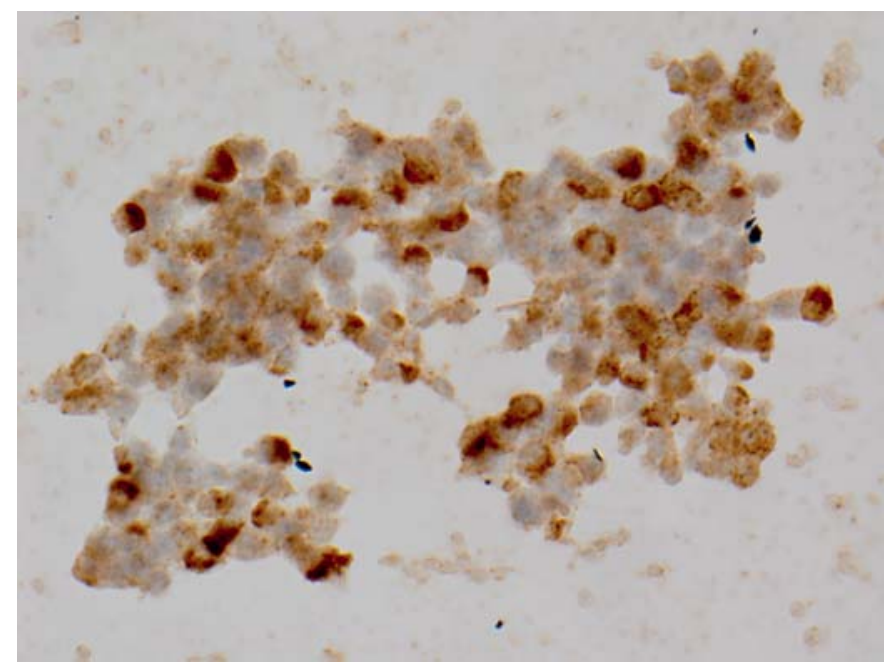

Fig. 4. Trypsin stain of alcohol-fixed direct smears from case 1 showing diffuse cytoplasmic staining of tumor cells. Immunocytochemical stain with hematoxylin counterstain. $\times 1,000$.

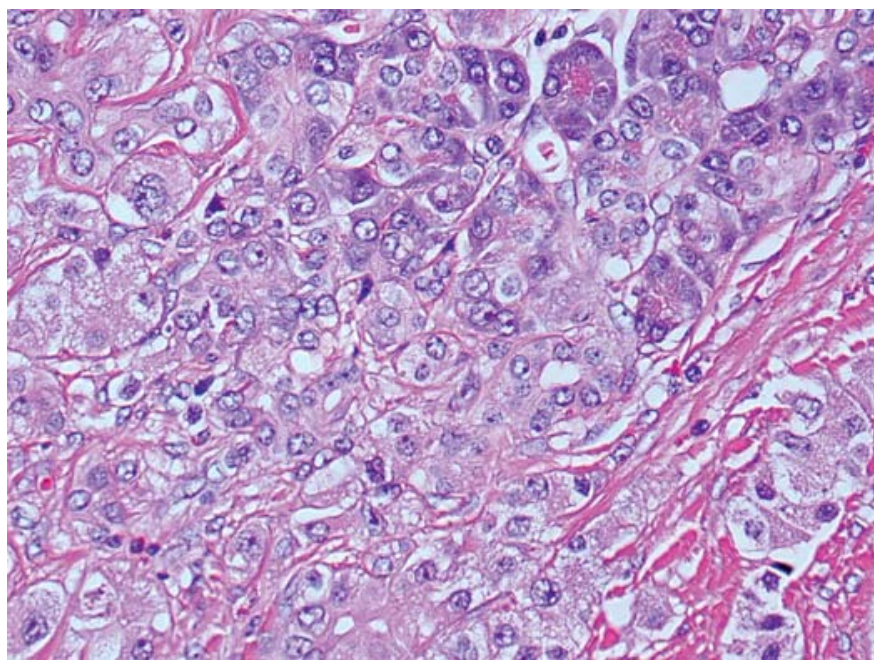

Fig. 5. Distal pancreatectomy specimen from case 2 showing nests and trabeculae of tumor cells with round to oval nuclei, granular to vesicular chromatin, occasional prominent nucleoli, and moderate delicate to finely granular eosinophilic cytoplasm. Note focal acinar cell differentiation comprised of more prominent nucleoli, amphophilic cytoplasm, and coarse pink cytoplasmic granules (upper right). Hematoxylin and eosin stain. $\times 600$.

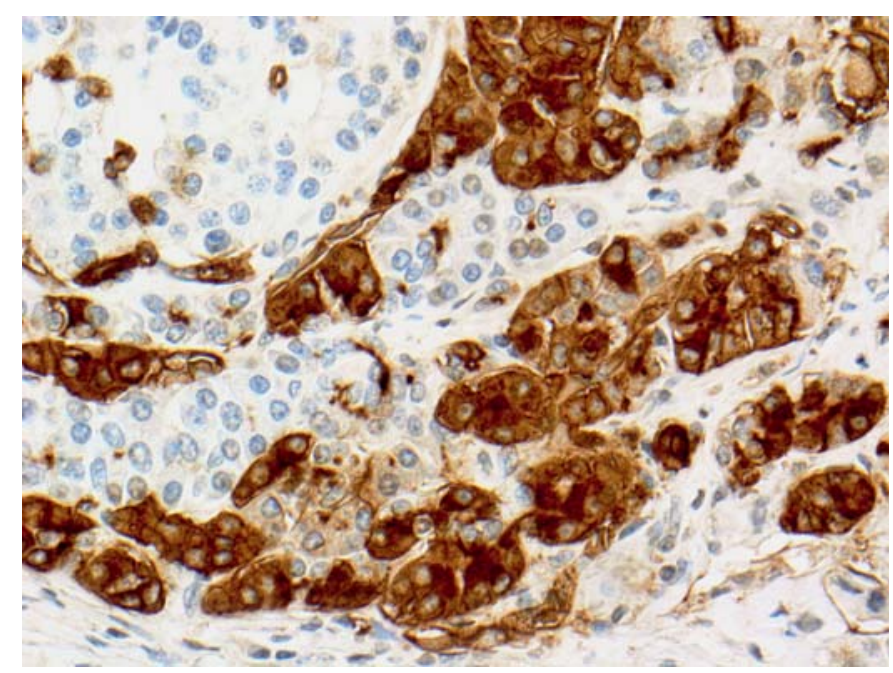

Fig. 7. Lipase stain of distal pancreatectomy specimen from case 2 showing distinct cytoplasmic staining of focal areas (greater than $25 \%$ ) within the tumor. IHC stain with hematoxylin counterstain. $\times 600$.

tumor cells without distinctive lines of differentiation. Acinar and endocrine components are established by diffuse, dual expression of IHC markers, sometimes within the same cell. Many cases are also confirmed by ultrastructural studies with similar findings $[2,4,5]$. The sec- 
ond pattern is seen in the vast majority of MAECs, almost always with a predominant acinar cell carcinoma (ACC) component, established by IHC.

It has been suggested that the clinical course of MAEC mirrors that of pure ACC, with uncommon long-term survival and more aggressive behavior than that of welldifferentiated endocrine neoplasms [1]; thus it is reasonable to consider that the predominant cell type (usually acinar) drives the tumor's biologic behavior. Some have considered that ACCs and MAECs may form a single tumor entity given their similar clinicopathologic characteristics despite their difference in percentage of scattered endocrine cells [6]. Interestingly, ACCs have been reported to have scattered endocrine cells in up to $42 \%$ of cases [7]. In addition, well-differentiated endocrine neoplasms have been reported to be positive for acinar cell markers in up to $66 \%$ of cases [8]. It is unclear whether these multiple lines of differentiation are a reflection of an originating pluripotent tumor cell, or genetic events are triggering divergent pathways within a developing neoplasm. Regardless, it is important to identify the acinar component of these mixed carcinomas on EUS-FNA, particularly in patients who are not surgical candidates, as these carcinomas may have different prognostic and therapeutic implications compared to well-differentiated endocrine neoplasms.

The pitfall of mistaking ACC or MAEC for PEN on cytology has been documented in the literature. In studies that have examined the cytologic features of pure ACC, greater than half the cases were erroneously diagnosed as PENs on FNA or touch preparation $[9,10]$. Of the MAEC cases reported with previous biopsy results, only 2 of 7 cases had correctly identified both acinar and endocrine components on FNA [11-17]. These cytology cases were signed out as 'ACC exhibiting endocrine differentiation' and 'special type of pancreatic tumor such as ACC or nonfunctioning islet cell tumor' $[11,12]$. Mistaking MAEC for PEN is not as well documented; however, it is likely to occur in a greater proportion of cases given the overlapping cytomorphologic characteristics with PEN, the possibility of sampling error, and the limited amount of material available for cell block and immunocytochemistry.

Indeed, in case 1, uniform neoplastic cells were enlarged, plasmacytoid, and arranged in loose clusters and single cells, features that may be seen in both ACC and PEN. Low power arrangements of acinar groups may look similar to endocrine-type rosettes, as documented in the literature [10]. Nuclear chromatin ranged from granular and somewhat 'salt-and pepper' to open, coarse, and more vesicular in appearance. In addition, prominent macronucleoli and granular cytoplasm, while characteristic of ACC [10], may also be seen in PENs on occasion $[18,19]$. The higher grade nuclei (more open chromatin, prominent macronucleoli), the more coarsely granular eosinophilic cytoplasm, and the presence of mitotic figures, binucleated cells, and pyknotic cells from case 1 may suggest more aggressive clinical behavior. In addition to excluding the possibility of an acinar cell component by IHC, another important consideration in the differential diagnosis would include a large cell neuroendocrine carcinoma. As the cytomorphologic distinction between ACC and PEN is already difficult, suggesting a dual-differentiated mixed carcinoma in a uniform cell population can be even more challenging.

Case 2 illustrates an issue likely due to sampling limitations. Smears showed cytomorphologic features compatible with a well-differentiated endocrine neoplasm. Obvious higher grade features were not evident on the cytologic material. While some cells had a suggestion of more prominent, frequent nucleoli and increased granular cytoplasm (fig. 3), morphologically distinct endocrine and acinar cell populations, as demonstrated on surgical excision, were not appreciated on smears. In this scenario, without both components clearly represented, precise recognition of a mixed tumor seems impossible.

IHC, while ultimately helpful, can contribute to the confusion as cases with diffuse strong staining of one or two endocrine markers may initially lead to the erroneous diagnosis of PEN, a neoplasm with a much higher incidence compared to MAEC. As alluded to above, higher grade features may be helpful in prompting a more extensive IHC workup to rule out the presence of an acinar cell component. In our study, trypsin or lipase positivity was demonstrated in our cytologic material, sometimes focally (case 2) and sometimes in a strongly diffuse manner in tumor cells already expressing endocrine markers (case 1). Thus, a component of acinar differentiation may be detected by immunocytochemistry (or even better, a cell block for IHC) in cases of MAEC.

It is important to remember that: (1) it may be difficult to ascertain the true percentages of acinar and endocrine cell components in an MAEC on cytologic preparations and (2) both pure ACCs and PENs, as noted previously, may have a minor component of endocrine and acinar cell differentiation $[7,8]$. Thus, while it is not always possible to make a definitive diagnosis of MAEC on cytology, raising the possibility of a mixed carcinoma may provide some guidance for the treatment team. Such wording in the diagnostic report may include 'malignant epithelioid 
neoplasm with features of both endocrine and acinar differentiation' and raise the possibility of a mixed carcinoma.

As noted above, Ki-67 IHC was also obtained for one of our cases (case 1). Although it can be difficult to estimate the proliferative index on cytologic preparations, an elevated Ki-67 (e.g. greater than $20 \%$ of nuclei stained), as with the presence of mitotic figures, may be helpful to suggest a clinically more aggressive tumor and prompt a more extensive immunocytochemical workup to exclude an acinar cell component.

In summary, we present two cases of MAEC, a rare mixed carcinoma, mistakenly diagnosed on initial cytology as PEN. It is important to be aware of this underreported diagnostic pitfall in cytology, especially as the incidence of MAEC may be higher than previously reported (with the increased utilization of IHC) and as there may be important prognostic and therapeutic implications for the patient. With greater awareness of the mixed pancreatic carcinoma category, the overlapping cytologic features of ACC and PEN in MAEC, and a lower threshold for utilizing immunocytochemistry or IHC on cell block, one may be able to raise the possibility of MAEC in the differential of malignant epithelioid neoplasms of the pancreas.

\section{Acknowledgements}

We gratefully acknowledge Peter Shintaku, PhD, the UCLA Immunohistochemical Laboratory, Maryann Gangi (at Integrated Oncology), and Genzyme Genetics for performing the IHC and immunocytochemistry for the cases reported and for technical assistance in manuscript preparation.

\section{Disclosure Statement}

No substantial financial support to disclose.

\section{References}

1 Hruban RH, Pitman MB, Klimstra DS: AFIP Atlas of Tumor Pathology, Series 4, Fascicle 6: Tumors of the Pancreas. Washington, American Registry of Pathology/Armed Forces Institute of Pathology, 2007, pp 211217.

-2 Ulich T, Cheng L, Lewin KJ: Acinar-endocrine cell tumor of the pancreas: report of a pancreatic tumor containing both zymogen and neuroendocrine granules. Cancer 1982; 50:2099-2105.

-3 Klimstra DS, Rosai J, Heffess CS: Mixed acinar-endocrine carcinomas of the pancreas. Am J Surg Pathol 1994;18:765-778.

-4 Ordóñez NG: Insulinoma with fibrillar inclusions and acinar cell elements. Ultrastruct Pathol 2001;25:485-495.

5 Frank M, Bittinger A, Rothmund M, Arnold R: Immunohistochemical analysis and clinical course of high-malignant composite endocrine-acinar cell carcinoma: a case report. Pancreas 1998;17:210-212.

6 Ohike N, Kosmahl M, Klöppel G: Mixed acinar-endocrine carcinoma of the pancreas: a clinicopathological study and comparison with acinar-cell carcinoma. Virchows Arch 2004;445:231-235.

7 Klimstra DS, Heffess CS, Oertel JE, Rosai J: Acinar cell carcinoma of the pancreas: a clinicopathologic study of 28 cases. Am J Surg Pathol 1992;16:815-837.
-8 Yantiss RK, Chang HK, Farraye FA, Compton CC, Odze RD: Prevalence and prognostic significance of acinar cell differentiation in pancreatic endocrine tumors. Am J Surg Pathol 2002;26:893-901.

-9 Stelow EB, Bardales RH, Shami VM, Woon C, Presley A, Mallery S, Lai R, Stanley MW: Cytology of pancreatic acinar cell carcinoma. Diagn Cytopathol 2006;34:367-372.

-10 Labate AM, Klimstra DL, Zakowski MF: Comparative cytologic features of pancreatic acinar cell carcinoma and islet cell tumor. Diagn Cytopathol 1997;16:112-116.

11 Imaoka H, Amano Y, Moriyama I, Itoh S, Yanagisawa A, Kinoshita Y: Endoscopic ultrasound-guided fine-needle aspiration of a mixed acinar-endocrine carcinoma: a case report. Am J Gastroenterol 2008;103:26592660.

12 Ogawa T, Isaji S, Yabana T: A case of mixed acinar-endocrine carcinoma of the pancreas discovered in an asymptomatic subject. Int J Pancreatol 2000;27:249-257.

13 Frank M, Bittinger A, Rothmund M, Arnold $\mathrm{R}$ : Immunohistochemical analysis and clinical course of high-malignant composite endocrine-acinar cell carcinoma: a case report. Pancreas 1998;17:210-212.
14 Moncur JT, Lacy BE, Longnecker DS: Mixed acinar-endocrine carcinoma arising in the ampulla of Vater. Hum Pathol 2002;33:449451.

15 Kyriazi MA, Arkadopoulos N, Stafyla VK, Yiallourou AI, Dafnios N, Theodosopoulos T, Kairi-Vassilatou E, Smyrniotis V: Mixed acinar-endocrine carcinoma of the pancreas: a case report and review of the literature. Cases J 2009;2:6481.

16 Kusafuka K, Bando E, Muramatsu K, Ito H, Tanizawa Y, Kawamura T, Mochizuki T, Terashima M, Nakajima T: Pancreatic-type mixed acinar-endocrine carcinoma with alpha-fetoprotein production arising from the stomach: a report of an extremely rare case. Med Mol Morphol 2009;42:167-174.

17 Soubra A, Faraj W, Saab J, Shamseddine A: Peri-ampullary mixed acinar-endocrine carcinoma. Rare Tumors 2011;3:e15.

18 Collins BT, Cramer HM: Fine-needle aspiration cytology of islet cell tumors. Diagn Cytopathol 1996;15:37-45.

19 Gu M, Ghafari S, Lin F, Ramzy I: Cytological diagnosis of endocrine tumors of the pancreas by endoscopic ultrasound-guided fineneedle aspiration biopsy. Diagn Cytopathol 2005;32:204-210. 